\title{
MONETARY POLICY IN THE OPEN ECONOMY REVISITED: PRICE SETTING AND EXCHANGE RATE FLEXIBILITY
}

\author{
Michael B. Devereux \\ Charles Engel \\ Working Paper 7665 \\ http://www.nber.org/papers/w7665 \\ NATIONAL BUREAU OF ECONOMIC RESEARCH \\ 1050 Massachusetts Avenue \\ Cambridge, MA 02138 \\ April 2000
}

We thank an anonymous referee for very helpful comments on an earlier draft. We have also benefitted greatly from comments by a large number of our colleagues in the profession. Engel acknowledges assistance from a National Science Foundation grant to the National Bureau of Economic Research. Devereux thanks the Social Sciences and Humanities Research Council of Canada for financial assistance. The views expressed herein are those of the authors and are not necessarily those of the National Bureau of Economic Research.

(C) 2000 by Michael B. Devereux and Charles Engel. All rights reserved. Short sections of text, not to exceed two paragraphs, may be quoted without explicit permission provided that full credit, including $\odot$ notice, is given to the source. 
Monetary Policy in the Open Economy Revisited:

Price Setting and Exchange Rate Flexibility

Michael B. Devereux and Charles Engel

NBER Working Paper No. 7665

April 2000

JEL No. F3, F4

\begin{abstract}
$\underline{\text { ABSTRACT }}$
This paper develops a welfare-based model of monetary policy in an open economy. We focus on the extent to which monetary policy should be employed in maintaining the exchange rate. The traditional approach maintains that exchange rate flexibility is desirable in the presence of real country-specific shocks that require adjustment in relative prices. However, in the light of empirical evidence on nominal price response to exchange-rate changes - specifically, that there appears to be a large degree of local-currency pricing in industrialized countries - the expenditure-switching role played by nominal exchange rates may be exaggerated in the traditional literature. In the presence of local-currency, we find that optimal monetary policy in response to real shocks pricing is fully consistent with fixed exchange rates. On the other hand, when real country-specific shocks are not important, and when a country's monetary sector is stable, the case for freely floating rates (a monetary policy in which exchange rates are not a consideration) is strengthened in the presence of local-currency pricing.
\end{abstract}

Michael B. Devereux

Department of Economics

1873 East Mall Bu Tower

University of British Columbia

Vancouver, BC 997 V6T 121

and CEPR

devm@unixg.ubc.ca
Charles Engel

Department of Economics University of Washington

Seattle, WA 98195

and NBER

cmengel@u.washington.edu 
In the last decade, one of the central issues facing monetary policy makers in open economies has been the degree to which policy choices should be affected by exchange-rate considerations. There is an abundance of different experiences around the world. Eleven countries of the European Union, by adopting a single currency and eliminating exchange rate changes, have abandoned independent national monetary policy. The currency boards of Hong Kong and Argentina have given their monetary policy completely over to the maintenance of an exchange rate fixed to the US dollar. On the other hand, the US and Japan, and smaller countries like Australia and Canada, have focused domestic monetary policy on the goal of achieving low and stable rates of inflation, allowing their exchange rates to fluctuate more or less freely.

There is little clear evidence on the overall success of alternative exchange rate regimes (e.g. Ghosh, Gulde, Ostroy and Wolf, 1997). Many critics have raised doubts about policies that fix the exchange rate in the context of the "optimum currency area" criteria, originally enumerated by Mundell (1961). They argue that free exchange rate movements would improve the functioning of capital markets and the allocation of resources in Europe, and in the Southeast Asian countries following the crisis of 1997-1998. ${ }^{1}$ Frankel (1999) takes an intermediate position, arguing that exchange-rate objectives for many countries should be but one of several concerns for monetary authorities.

This paper develops a welfare-based model of monetary policy in an open economy. We focus on the extent to which monetary policy should be employed in maintaining a fixed exchange rate. The analysis is based around two very traditional ideas, central to the recent debate on exchange rate policy: On the one hand exchange rate flexibility is desirable in the presence of real country-specific shocks that require adjustment in relative prices. But on other hand, a fixed exchange rate allows a country to inherit monetary stability from a regime that has manifested strong monetary discipline. 
The modern case for flexible exchange rates goes back to Friedman (1953). Real countryspecific productivity or demand shocks require adjustment of relative price levels between countries. If nominal prices adjusted quickly, Friedman argues, the choice of exchange-rate regime would be irrelevant because the relative price adjustment could be achieved by nominal price changes:

If internal prices were as flexible as exchange rates, it would make little economic difference whether adjustments were brought about by changes in exchange rates or by equivalent changes in internal prices. But this condition is clearly not fulfilled. The exchange rate is potentially flexible in the absence of administrative action to freeze it. At least in the modern world, internal prices are highly inflexible.

Freely floating exchange rates allow the needed relative price adjustment to occur instantaneously when nominal goods price-adjustment is sluggish. As Feldstein (1992) puts it,

Either form of adjustment [exchange-rate or price] can bring the real exchange rate to its equilibrium value, but a decline in domestic prices is likely to require a period of increased unemployment. It would certainly be better to have a decline in the nominal exchange rate. The shift to a single currency in Europe would preclude such nominal exchange-rate adjustments and force real exchange-rate reductions to be achieved through lower local wages and prices.

This type of reasoning lies behind the recommendation of the optimum-currency area literature that countries subject to sizable country-specific real shocks should not target exchange rates with monetary policy. ${ }^{2}$ But the argument relies on the notion that exchange-rate movements have a large immediate impact on aggregate demand, by allowing instantaneous adjustment of relative prices. Recent empirical work, however, indicates that in the short run there is very little response of consumer prices to changes in nominal exchange rates. ${ }^{3}$ The short-run adjustment role of nominal exchange rates is eliminated to the extent that consumer prices are unresponsive to exchange rate changes: the so-called "expenditure-switching effect" may be negligible.

1 See for example, Feldstein (1992) or Obstfeld (1997) on Europe, and Sachs (1997) on Asia..

See Eichengreen (1994), for example, for a survey of optimum currency considerations.

3 See Mussa (1986), Engel (1993, 1999), Engel and Rogers (1996), and Parsley and Wei (1996, 1999), for example. 
There is a voluminous literature on optimal monetary policy in open economies under price stickiness. $^{4}$ But none of that analysis has been based on choice-theoretic models, and therefore has lacked an adequate welfare criterion. In this paper we develop a two-country, stochastic, stickyprice general equilibrium optimizing model, drawing on the work of Obstfeld and Rogoff (hereinafter referred to as OR, 1995, 1998). To conduct a realistic analysis of the role of the exchange rate in monetary policy, we allow for both country specific productivity or supply shocks, and country specific monetary or velocity shocks. We evaluate optimal monetary policy using the welfare of consumers as the criterion. As in OR (1998), our model is simple enough to admit an exact solution for prices, exchange rates and all real allocations. An implication of this is that monetary policy rules affect both volatility and levels of macroeconomic variables. This has an important implication for the conduct of monetary policy with respect to the exchange rate.

While we are solely concerned with monetary policy under sticky prices, a critical distinction in our analysis is the currency in which prices are set. We allow two different specifications of price-setting. Our first specification follows OR (1995, 1998), and implicitly the Friedman and Feldstein analyses, assuming that nominal prices are preset in the currency of the producer (denoted producer-currency pricing or PCP). As a result, when exchange rates fluctuate, imported goods prices move one-for-one with exchange rates. But we also allow another type of price stickiness -prices that are preset in consumers' currency (denoted local-currency pricing or LCP). ${ }^{5}$ This specification is more in accord with the empirical findings cited above.

The model delivers a strikingly simple representation of the objective functions of monetary policy ${ }^{6}$. Under PCP, monetary authorities in each country should attempt to minimize a linear

\footnotetext{
4 See Devereux and Engel (1998) for a long but partial list of citations.

5 Notably Betts and Devereux (1996, 2000a) have also made this assumption in open-economy sticky-price models, but not in a fully stochastic model which is required to analyze optimal monetary policy.

${ }^{6}$ This contrasts particularly with the older literature on optimal monetary policy in open economies, which often employed ad hoc objective functions consisting of output and balance of trade volatility. In our analysis the balance of trade is an entirely irrelevant objective for monetary policy.
} 
combination of consumption variance, exchange rate variance, and the covariance of consumption and exchange rates with country specific productivity shocks. Under LCP, the appropriate monetary policy objective ignores the exchange rate, rather minimizing a linear combination of consumption variance and the covariance of consumption with productivity shocks.

The distinction between price-setting specifications is critical for our analysis of the adjustment benefits of the exchange rate in face of country-specific productivity shocks. Under the Friedman type of price stickiness - PCP - fixed exchange rates are strictly sub-optimal when real country-specific shocks dominate. The exchange rate must be employed as part of optimal monetary policy in order to achieve a change in relative prices, precisely as described by Friedman. In fact, with exchange-rate flexibility, optimal monetary policy can replicate the equilibrium of the economy with fully flexible prices. Flexible exchange rates are a perfect substitute for flexible goods prices. In contrast, exchange-rate flexibility confers no advantage if prices are set in consumers' currencies, (as the empirical evidence suggests). Under LCP, an optimal monetary rule does not utilize exchange rate movements at all! Optimal monetary policy, followed by policy makers in each country, is in fact fully consistent with fixed exchange rates. ${ }^{7}$

A methodological implication of our results relates to the appropriate mapping between consumer's utility functions and monetary policy objectives. In our model, a simple Taylor-series approximation of utility would suggest that monetary rules should minimize consumption variance alone. But our exact analysis shows that the optimal rule should take account of both consumption variance and expected consumption. In fact, it is the incorporation of expected consumption into the monetary policy objective leads the policy-maker to add exchange rate variance, and the

\footnotetext{
${ }^{7}$ An implication of our analysis is that an optimal monetary policy outcome involves policy-makers in both countries choosing optimal rules. Although monetary policy is described as a game between policy makers, in this model there is no welfare losses from independent monetary policy-making, and no therefore no gains (or losses) from policy coordination.
} 
covariance of consumption and exchange rates with productivity disturbances, to the linear policy objective function to be minimized.

Our formal welfare analysis also allows us to consider the optimal degree of exchange-rate intervention for a country that experiences shocks to money supply or velocity. In accordance with traditional thinking, we find that if the variance of domestic monetary shocks is sufficiently large, it would like to inherit the monetary stability of a country that has a track record of monetary discipline. But if it has a very stable monetary sector relative to the outside world, it would prefer more exchange rate flexibility. But we also find here that the type of price-setting behavior is important. Under PCP, a country would never choose a clean float, even if it had a completely stable monetary sector, because the volatility of exchange rates imparts a direct welfare cost on expected consumption. On the other hand, with LCP, exchange rate volatility causes no independent welfare cost, and a float is fully optimal for a country with complete monetary stability. Thus, while the traditional case for floating rates as providing an expenditure-switching mechanism is nullified under LCP, the case is strengthened when considering monetary factors for a country with a stable monetary sector.

Section 1 sets out the general equilibrium model. In section 2, we discuss features of the solution to the model. The optimal monetary policy rules are derived and examined in section 3 . Some conclusions follow. Most of the derivations of our results are contained in an Appendix at the end of the paper. 


\section{The Model}

The model economy has the following structure. There are two countries, home and foreign. In each country, households maximize expected lifetime utility, taking prices and wages as given. Firms are monopolistic competitive, and maximize utility for their owners. There are shocks to both money supply and to production technologies.

We work with two alternative specifications for the pricing of consumer goods. In all specifications, producers must set prices prior to the realization of shocks. This is an institutional constraint in our model, although it can be justified by the presence of menu-costs of price adjustment. Prices fully adjust to all shocks after one period; i.e., there is no persistence to the price-adjustment process ${ }^{8}$. In the first specification, producers set prices in terms of their own currency. For example, the home currency price of home goods is set, and unresponsive to monetary shocks. The price for home goods paid by foreign consumers then changes when there is an unexpected exchange rate change. We denote this specification 'producer-currency pricing', or PCP.

In the other specification, producers set prices in consumers' currencies. For example, home firms set one price for home-country consumers in the home currency and another price for foreigncountry consumers in the foreign currency. Unexpected changes in exchange rates have no effect on consumer prices, either at home or in the foreign country. This specification is referred to as one of 'local-currency pricing', or LCP.

It is natural to focus on the two extreme cases of price-setting behavior: complete PCP or complete LCP. PCP is the traditional assumption in open economy macroeconomics (see for instance, Obstfeld and Rogoff 1996). Moreover, it is the central core behind the defense of flexible exchange rates of many writers from Friedman onwards. But there seems to be widespread 
evidence for LCP in at least in North American and Europe, as discussed in the introduction. On the other hand, for developing economies, and especially high inflation economies, PPP seems to hold more accurately in the sense that the nominal exchange rate is significantly more variable than the real exchange rate (e.g. Obstfeld 1998). In addition, there is evidence that the link between exchange rates and imported goods prices is much closer for some emerging market economies than for the economies of the OECD (Takagi and Yoshida 1999).

Betts and Devereux (2000a) develop a model where PCP and LCP coexist, as a fraction of firms set their export prices in their own currency, while the rest set prices in consumers currency, and the fraction can vary between zero and one. But incorporating this arrangement in our model would mean sacrificing the ability to obtain exact solutions. Moreover, because we have essentially identified either extreme of this continuum, this alternative approach would provide little extra insight into the properties of exchange rate regimes or monetary policies.

\section{Consumers}

The representative consumer in the home country is assumed to maximize

$$
U_{t}=E_{t}\left(\sum_{s=t}^{\infty} \beta^{s-t} u_{s}\right), \quad 0<\beta<1
$$

where

$$
u_{s}=\frac{1}{1-\rho} C_{s}^{1-\rho}+\frac{\chi}{1-\varepsilon}\left(\frac{M_{s}}{P_{s}}\right)^{1-\varepsilon}-\eta L_{s}, \quad \rho>0, \varepsilon>0
$$

$C$ is a consumption index that is a geometric average of home and foreign consumption ${ }^{9}$ :

\footnotetext{
${ }^{8}$ This assumption is made so that monetary rules can be derived analytically. Qualitatively, it affects none of results. To apply our model to the realistic design of optimal monetary policies, it would be necessary to introduce more persistent price stickiness, as in Rotemberg and Woodford (1997), or Chari, Kehoe and McGrattan (1997).

${ }^{9}$ All variables in this section are implicitly functions of the state of the world $z_{t} \in Z^{t}$, where $Z^{t}$ is a suitably defined set of all possible states at time $t$. To economize on space, we omit this state notation until we explicitly define the stochastic processes governing money and productivity shocks in the next section.
} 


$$
C=\frac{C_{h}^{n} C_{f}^{1-n}}{n^{n}(1-n)^{1-n}}
$$

We assume that there are $n$ identical individuals in the home country, $0<n<1 . \quad C_{h}$ and $C_{f}$ are indexes over consumption of goods produced at home and in the foreign country, respectively (see the Appendix for further details). The elasticity of substitution between goods produced within a country is $\lambda$, where $\lambda>1$. There is a unit elasticity of substitution between the home goods and foreign goods indexes. $M / P$ are domestic real balances, and $L$ is the labor supply of the representative home agent.

This is a special functional form for utility, but it has the appealing property that it allows us to derive exact expressions for welfare across a range of alternative exchange rate regimes and monetary policies. It is a slight variant of the specification used by OR (1998). While the separability of the utility function may be problematic for analyzing some aspects of exchange-rate and current-account dynamics, it is very helpful in making the model more tractable analytically. Bacchetta and van Wincoop (1998) have emphasized (in a two-period framework) the importance of non-separabilities of leisure and consumption for the impact of the choice of exchange-rate regime on the volume of trade.

The price index, $P$, is defined by

$$
P=P_{h}^{n} P_{f}^{1-n},
$$

where $P_{h}$ and $P_{f}$ are price indexes for home and foreign goods, respectively.

There are $1-n$ identical individuals in the foreign country. Their preferences are identical to those of the home country, except being functions of foreign real balances and foreign labor supply.

We assume that there are complete asset markets. Residents of each country can purchase a full set of state-contingent nominal bonds. When the law of one price holds (as it does under the 
PCP specification), consumption risk is completely shared, even without complete assets markets. ${ }^{10}$

But under the LCP specification, the law of one price does not hold. We consider the assumption of complete asset markets to be one of convenience, which approximates the assumption of perfect capital mobility, while ruling out dynamic effects of wealth redistribution, which in both a quantitative and welfare sense are likely to be of second order importance.

Consumers obtain wages $W_{t}$ from working, receive profits from firms and transfers from government, and get payments on state contingent bonds. They choose their holdings of money balances, consumption, labor supply and bonds. The money demand equation for the representative home-country resident is given by:

$$
\frac{M_{t}}{P_{t}}=\frac{\chi^{1 / \varepsilon} C_{t}^{\rho / \varepsilon}}{\left(1-E_{t} d_{t+1}\right)^{1 / \varepsilon}}
$$

where $E_{t} d_{t+1}$ is the inverse of the gross nominal interest rate, and $d_{t+1}=\left(\beta \frac{C_{t+1}^{-\rho} P_{t}}{C_{t}^{-\rho} P_{t+1}}\right)$.

The optimal trade-off between consumption and leisure implies:

$$
\frac{W_{t}}{P_{t} C_{t}^{\rho}}=\eta
$$

When consumers have access to a full set of state contingent bonds, Chari, McGrattan, and Kehoe (1997) show that the following risk-sharing condition obtains

$$
\frac{S_{t} P_{t}^{*}}{P_{t}}=\Gamma_{0}\left(\frac{C_{t}}{C_{t}^{*}}\right)^{\rho}
$$

where $S_{t}$ is the home currency price of foreign currency, and $\Gamma_{0}$ is a constant, depending on initial conditions. ${ }^{11}$ Consumption will differ across the two countries only to the extent that there are

\footnotetext{
${ }^{10}$ As OR (1998) emphasize, this follows from the property of unit elasticity of substitution between home and foreign composite goods. See also Cole and Obstfeld (1991) for an analysis of why terms of trade changes can serve as a substitute for capital mobility.

${ }^{11} \mathrm{We}$ assume $\Gamma_{0}=1$.
} 
changes in the real exchange rate. In the PCP specification, since purchasing power parity holds, we have, as OR (1998) derive, $C_{t}=C_{t}^{*}$.

\section{Government}

Government increases the money supply with direct transfers. The government budget constraint (in per capita terms) is simply

$$
M_{t}=M_{t-1}+T_{t}
$$

In the discussion below, we will be more specific about the form of the optimal monetary rules.

\section{Firms}

Firms are monopolistic competitors. The production function for firm $i$ is given by:

$$
Y_{i t}=\theta_{t} L_{i t}
$$

where $L_{i t}$ is employment of firm $i$ at time $t$, and $\theta_{t}$ represents a country-specific productivity shock.

The objective of the domestic firms is to set prices to maximize the expected utility of the owners.

Because there are complete markets, it does not matter whether the owners of firms are home or foreign residents. But prices must be set before information about random money supplies and productivity shocks is known.

The optimization problem can be expressed as maximizing the expected present value of profits using the market nominal discount factor for the owners of the firm. The solutions for optimal pricing rules are given in Table 1.

Under the PCP specification, firms choose a single price, in domestic currency, to maximize the state-contingent value of profits. Take for instance the optimal price set by the home firm, $P_{h t i}^{P C P}=P_{h t}^{P C P}$, given in the top left hand entry of Table 1. In a world of certainty, the price would simply be a fixed mark-up over unit labor costs. Here, there is an additional mark-up arising from the covariance of nominal wages with $C_{t}^{1-\rho}$. The term represents a risk premium arising from the 
covariance of the firm's profits with the marginal utility of consumption. ${ }^{12}$ Specifically, the ex post increase in costs from lowering prices by one unit is proportional to $P_{h t}^{-\lambda-1} C_{t} W_{t}$, while the increase in revenue is proportional to $P_{h t}^{-\lambda} C_{t}$. Then weighting each side by the discount rate for period $t$ - 1 , and equating in expectations, we arrive at the optimal price as given by the expression in Table 1.

\section{Table 1}

\section{Optimal Prices}

\begin{tabular}{|c|c|}
\hline$P_{h t}^{P C P}=\frac{\lambda}{\lambda-1} \frac{E_{t-1}\left(\frac{C_{t}^{1-\rho} W_{t}}{\theta_{t}}\right)}{E_{t-1}\left(C_{t}^{1-\rho}\right)}$ & $P_{h t}^{L C P}=P_{h t}^{P C P}$ \\
\hline$P_{h t}^{* P C P}=P_{h t}^{P C P} / S_{t}$ & $P_{h t}^{* L C P}=\frac{\lambda}{\lambda-1} \frac{E_{t-1}\left(\frac{W_{t} C_{t}^{* 1-\rho}}{S_{t} \theta_{t}}\right)}{E_{t-1}\left(C_{t}^{* 1-\rho}\right)}$ \\
\hline$P_{f t}^{* P C P}=\frac{\lambda}{\lambda-1} \frac{E_{t-1}\left(\frac{C_{t}^{* 1-\rho} W_{t}^{*}}{\theta_{t}^{*}}\right)}{E_{t-1}\left(C_{t}^{* 1-\rho}\right)}$ & $P_{f t}^{* L C P}=P_{f t}^{* P C P}$ \\
\hline$P_{f t}^{P C P}=S_{t} P_{f t}^{* P C P}$ & $P_{f t}^{L C P}=\frac{\lambda}{\lambda-1} \frac{E_{t-1}\left(\frac{S_{t} C_{t}^{1-\rho} W_{t}^{*}}{\theta_{t}^{*}}\right)}{E_{t-1}\left(C_{t}^{1-\rho}\right)}$ \\
\hline
\end{tabular}

The law of one price holds for the price charged to foreigners by the home firm, $P_{h t}^{* P C P}$, in the PCP model. Analogous relationships hold for the prices set by the foreign firms, $P_{f t}^{* P C P}$ and $P_{f t}^{P C P}$

Under the LCP specification, the firm chooses two different prices - one to charge residents of its own country, and one to charge residents of the other country. The price charged by the home

\footnotetext{
${ }^{12}$ See OR (1998) and Devereux and Engel (1998) for further discussion of the pricing equations.
} 
firm to the home residents is given by the same expression as in the PCP case. The price charged to foreign residents, $P_{h t}^{* L C P}$ is explained as follows. In selling to the foreign market, the firm calculates that the ex post increase in costs from lowering prices by one unit is proportional to $P_{h t}^{*-\lambda-1} C_{t}^{*} W_{t}$, while the increase in revenue is proportional to $P_{h t}^{*-\lambda} C_{t}^{*} S_{t}$. Weighting both sides by the marginal utility of the home consumer, using the risk sharing rule (1.4), and equating, we obtain the expression for $P_{h t}^{* L C P}$ in Table 1. Note that with perfect certainty, the price would be set so that its home currency value is a fixed mark-up over unit labor costs. Likewise, under LCP, the price charged by foreign firms to its own residents is the same as under PCP, but the price charged to home-country consumers is not. ${ }^{13}$

Given equal consumption at home and abroad, the goods-market equilibrium condition in the home country under PCP can be written as

$$
\theta_{t} L_{t}=\frac{P_{t} C_{t}}{P_{h t}}
$$

With LCP the goods-market equilibrium in the home country is written as:

$$
\theta_{t} L_{t}=n \frac{P_{t} C_{t}}{P_{h t}}+(1-n) \frac{P_{t}^{*} C_{t}^{*}}{P_{h t}^{*}}
$$

For suitably defined stochastic processes governing $M_{t}, M_{t}^{*}, \theta_{t}$, and $\theta_{t}^{*}$, the 13 functions (of the state of the world) $C, C^{*}, P_{h}, P_{h}^{*}, P_{f}, P_{f}^{*}, P, P^{*}, S, W, W^{*}, L$, and $L^{*}$, are determined by the 13 equations (1.1) and its foreign equivalent, (1.2) and its foreign equivalent, (1.3) and its foreign equivalent, (1.4), (1.5) (under PCP) or (1.6) under LCP and its foreign equivalent, and the four pricing equations from Table 1.

\footnotetext{
${ }^{13}$ OR (2000) have criticized the LCP assumption on the grounds that it contradicts some empirical regularities concerning the terms of trade - that an appreciation of a country's currency tends to be associated with an improvement in its terms of trade. LCP pricing implies the opposite relationship. But Devereux, Engel and Tille (1999) show that the LCP model is equivalent to one in which producers price in their own currency, but in which intermediaries set prices for consumers in local currencies. That model predicts appreciations lead to improvements in the terms of trade.
} 


\section{Model Solution}

The economy is exposed to two types of disturbances; shocks to money supplies (nominal shocks) and shocks to productivity (real shocks) ${ }^{14}$. We let the productivity disturbances, $\theta_{t}$ and $\theta_{t}^{*}$, be governed by the following processes

$$
\begin{aligned}
& \ln \theta_{t}=\delta \ln \theta_{t-1}+u_{t} \\
& \ln \theta_{t}^{*}=\delta \ln \theta_{t-1}^{*}+u_{t}^{*}
\end{aligned}
$$

where $0 \leq \delta \leq 1$, and $u_{t}$ and $u_{t}^{*}$ are mean-zero i.i.d. normally distributed random variables.

The log money supply for each economy is given by:

$$
\begin{gathered}
m_{t}=m_{t-1}+v_{t}+\gamma\left(s_{t}-E_{t-1} s_{t}\right)+a_{1} u_{t}+a_{2} u_{t}^{*} \\
m_{t}^{*}=m_{t-1}^{*}+v_{t}^{*}+b_{1} u_{t}^{*}+b_{2} u_{t}
\end{gathered}
$$

These monetary rules allow for the authorities to react directly to productivity shocks arising from either country. In addition, (2.1) allows the home country to choose a feedback intervention rule for adjusting money to movements in the exchange rate. When $\gamma<0$, this rule displays 'leaning against the wind'. For given values of $a_{1}$ and $a_{2}$, the value of $\gamma$ defines the exchange rate regime. When $\gamma=0$, we say that the exchange regime is a free float, while as $\gamma \rightarrow-\infty$, the feedback rule prevents the exchange rate from adjusting at all, so that we have a fixed exchange rate regime. The $v_{t}$ and $v_{t}^{*}$ terms represent uncontrollable mean-zero i.i.d. normally distributed disturbances to the supply of money ${ }^{15}$.

Because all shocks are log-normal, the solution of the model will take on a log-normal distribution. From section 1, all equations save for (1.2) are log-linear, and therefore, in the

\footnotetext{
${ }^{14}$ We ignore shocks to government spending. Since utility is linear in labor effort in this economy, government spending shocks have no effect on consumption. There is therefore no role for monetary policy in responding to government spending shocks.

${ }_{15}$ These might be thought of as shocks resulting from financial innovation. They are also formally equivalent to velocity disturbances in the solution of the model.
} 
presence of log-normal distributions, offer exact solutions. But the money market equilibrium conditions in each country require an approximation. Following OR (1998), the appendix shows that the following approximation can be employed to represent an equilibrium in the home country money market.

$$
m_{t}-p_{t}=\frac{\rho}{\varepsilon} c_{t}-\frac{1}{i \varepsilon}\left(E_{t} p_{t+1}+\rho E_{t} c_{t+1}-p_{t}-\rho c_{t}\right)+\Gamma_{m}
$$

where $\Gamma_{m}$ is a constant. An analogous condition may be derived for the foreign country. The accuracy of this approximation may be gauged by the extent to which the parameter $\varepsilon$ deviates from unity. It is shown in Devereux and Engel (1998) that in the case $\varepsilon=1$, the money market clearing equation may be solved exactly, and thus, (2.3) involves no approximation.

\section{The Flexible Price Solution}

To get a perspective on the effect of price rigidities and to understand the motivation for optimal monetary rules, it is useful to see the solution to the model in an environment of fully flexible prices. With flexible prices, the profit maximizing price rules obtain in each state of the world, and not just in expectation. We may then establish that

$$
C_{t}=\left(\frac{\lambda \eta}{\lambda-1}\right)^{-\frac{1}{\rho}}\left(\theta_{t}^{n} \theta_{t}^{*(1-n)}\right)^{\frac{1}{\rho}}
$$

Consumption is unaffected by money shocks, but depends positively on both home and foreign productivity shocks. Employment in each country is also equated in the flexible price economy:

$$
L_{t}=\left(\frac{\lambda \eta}{\lambda-1}\right)^{-\frac{1}{\rho}}\left(\theta_{t}^{n} \theta_{t}^{*(1-n)}\right)^{\frac{1-\rho}{\rho}}
$$

Finally the terms of trade under flexible prices are given by: 


$$
\frac{P_{h t}}{S_{t} P_{f t}}=\frac{\theta_{t}^{*}}{\theta_{t}}
$$

A nice feature arising from the log-normality of shocks is that we can easily express expected utility of consumption in terms of the mean of consumption and the variance of the log of consumption:

$$
E C^{1-\rho}=(E C)^{1-\rho} \exp \left(-\frac{\rho(1-\rho)}{2} \sigma_{c}^{2}\right)
$$

Since expected labor supply will be a linear function of $E C^{1-\rho}$, it turns out that to understand optimal policy it is sufficient to understand the effects of policies on the mean and variance of consumption.

The Appendix gives the solution for the variance and the conditional expectation of consumption with flexible prices. Consumption variance is positively related to the variance of productivity shocks. Expected (conditional) consumption is increasing in the variance of $(\log )$ consumption.

\section{Producer-Currency Pricing}

Under producer currency pricing, we may obtain an explicit solution for the exchange rate

$$
s_{t}-E_{t-1} s_{t}=\frac{\left(a_{1}-b_{2}\right)}{(1-\gamma)} u_{t}+\frac{\left(a_{2}-b_{1}\right)}{(1-\gamma)} u_{t}^{*}+\frac{\left(v_{t}-v_{t}^{*}\right)}{(1-\gamma)}
$$

If the feedback rules on productivity shocks are identical across countries, then the exchange rate will be independent of productivity shocks. As the degree of exchange rate intervention rises (i.e. $\gamma \rightarrow-\infty$ ), the influence of all shocks on the exchange rate diminishes. We can show (see the Appendix) that

$$
c_{t}=E_{t-1} c_{t}+\Lambda_{1} u_{t}+\Lambda_{2} u_{t}^{*}+\frac{\phi n}{1-\gamma} v_{t}+\frac{\phi(1-\gamma-n)}{(1-\gamma)} v_{t}^{*}
$$


where $\Lambda_{1}=\phi\left(\frac{n\left(a_{1}-b_{2}\right)}{1-\gamma}+b_{2}\right)+\psi n, \Lambda_{2}=\phi\left(\frac{n\left(a_{2}-b_{1}\right)}{1-\gamma}+b_{1}\right)+\psi(1-n), \phi=\frac{(1+i \varepsilon)}{\rho(1+i)}$, and $\psi=\frac{\delta i(\varepsilon-1)}{\rho(1+i)(1+i \varepsilon-\delta)}$

Unlike the flexible price solution, consumption may be either increasing or decreasing in productivity shocks, in the absence of monetary rules that target these shocks. When a persistent (i.e. $\delta>0$ ) positive technology shock occurs, it raises expected future consumption, and reduces expected future prices. With $\varepsilon>1$, the rise in expected future consumption dominates the fall in expected future prices, so the nominal interest rate rises. Then there is present period excess supply of real money balances, which with sticky prices, increases current consumption. On the other hand, when $\varepsilon<1$, a productivity shocks leads the nominal interest rate to fall, and therefore current consumption falls.

Consumption is increasing in shocks to the money supply of both countries. As shown in OR (1995), a foreign monetary expansion will lead to a home country appreciation, a fall in the price level, and an expansion in real balances. As a result, consumption will rise. A home money expansion on the other hand will directly increase consumption, but part of that is dissipated by an exchange rate depreciation. So consumption rises by less than proportionally to the monetary expansion. Intuitively, the greater is the degree of foreign exchange rate intervention (the more negative is $\gamma$ ), the smaller will be the impact of home monetary shocks on consumption.

With sticky prices, the expected level of consumption takes on the form

$$
E_{t-1} C_{t}=\Phi(t-1) \exp \left(-\frac{(1-\rho) \sigma_{c}^{2}}{2}-\frac{n(1-n)}{2 \rho} \sigma_{s}^{2}-\frac{\tilde{\sigma}_{u}^{2}}{2 \rho}+\frac{\tilde{\sigma}_{c u}}{\rho}+n(1-n) \frac{\left(\sigma_{s u}-\sigma_{s u^{*}}\right)}{\rho}\right)
$$

where $\Phi(t-1)$ is a function of last period productivity shocks, and $\tilde{\sigma}_{u}^{2}=n \sigma_{u}^{2}+(1-n) \sigma_{u^{*}}^{2}$, $\tilde{\sigma}_{c u}=n \sigma_{c u}+(1-n) \sigma_{c u^{*}}$. Expected consumption depends upon consumption variance, exchange rate variance, the variance of productivity shocks, and covariance terms. 
Expected consumption is increasing (decreasing) in consumption volatility as $\rho>1$, $(\rho<1)$. It is always decreasing in exchange rate volatility, and for given consumption and exchange rate volatility, expected consumption is decreasing in the variance of technology shocks. To see the relationship between consumption volatility and expected consumption, note that from equation (1.3), the wage is proportional to $C^{\rho}$. If $\rho>1$, this means that the wage is negatively correlated with the firm's marginal utility-discounted demand, $C^{1-\rho}$. Therefore, given the price setting problem facing the firm, the price will be lower the higher is the variance of consumption, when $\rho>1$. But a lower price implies a higher expected consumption.

Higher exchange rate volatility increases expected marginal costs directly, since when there is full pass-through of exchange rates to domestic prices, the CPI's and therefore wages will be affected by exchange rate volatility. From the pricing equations in Table 1, it can be shown that higher exchange rate variance raises average prices and leading to lower expected consumption. In this sense the model implies a pure welfare cost of exchange rate volatility. In the presence of nominal rigidities and optimal pricing, exchange rate volatility leads to higher average prices. Of course this welfare effect of exchange rate volatility arises because of nominal price rigidities. When prices are fully flexible, there is no effect of exchange rate volatility on the average level of prices.

To compute welfare, we will need to evaluate expected employment. Under PCP expected employment is

$$
E_{t-1} L_{t}=\frac{(\lambda-1) E_{t-1} C_{t}^{1-\rho}}{\lambda \eta},
$$

Expected employment for the foreign country is identical to (2.9). 


\section{Local-Currency Pricing}

Under local-currency pricing, PPP will not generally hold. Thus, home and foreign consumption will differ. We may combine the pricing equations, the money supply rules (equations (2.1) and (2.2)) and the money-market clearing condition (2.3) to obtain the value of expected home country consumption:

$$
c_{t}=E_{t-1} c_{t}+\Omega_{1} u_{t}+\Omega_{2} u_{t}^{*}+\phi\left(\frac{1}{1-\phi \gamma \rho} v_{t}+\frac{\gamma \rho \phi}{1-\phi \gamma \rho} v_{t}^{*}\right)
$$

where $\Omega_{1}=\phi\left(\frac{\left(a_{1}-\gamma \rho \phi b_{2}\right)}{(1-\gamma \phi \rho)}\right)+\psi n$ and $\Omega_{2}=\phi\left(\frac{\left(a_{2}-\gamma \rho \phi b_{1}\right)}{(1-\gamma \phi \rho)}\right)+\psi(1-n)$.

Home country consumption is affected by both home and foreign productivity shocks, both because home money responds to productivity shocks in both countries, and because nominal interest rates are influenced by persistent productivity shocks. But foreign money shocks affect home consumption only due to the exchange rate intervention undertaken by the home country. In the absence of intervention, home consumption would be unaffected by foreign money shocks, since these shocks do not pass through to domestic goods prices under LCP.

In the same way, we may establish that foreign country consumption is

$$
c_{t}^{*}=E_{t-1} c_{t}^{*}+\Omega_{2}^{*} u_{t}+\Omega_{1}^{*} u_{t}^{*}+\phi v_{t}^{*}
$$

where $\Omega_{1}^{*}=\phi b_{1}+\psi(1-n)$, and $\Omega_{2}^{*}=\phi b_{2}+\psi n$. Foreign consumption is unaffected by home country money shocks, under LCP.

The solution for expected (home country) consumption under LCP is derived in the Appendix as:

$$
E_{t-1} C_{t}=\Phi(t-1) \exp \left(-\frac{(1-\rho) \sigma_{c}^{2}}{2}-\frac{\tilde{\sigma}_{u}^{2}}{2 \rho}+\frac{\tilde{\sigma}_{c u}}{\rho}\right)
$$

Unlike (2.8), this does not depend on the distribution of the exchange rate. Without exchange rate pass-through, wages are not directly affected by exchange rates. Therefore, average 
prices and expected consumption are unaffected by exchange rate volatility. Expected consumption for the foreign country is symmetric to equation (2.12).

Expected employment in the LCP specification is determined by using equation (1.6) above. Again, expected employment is identical for home and foreign countries, and given by:

$$
E_{t-1} L_{t}=\frac{n(\lambda-1) E_{t-1} C_{t}^{1-\rho}}{\lambda n}+\frac{(1-n)(\lambda-1) E_{t-1} C_{t}^{*(1-\rho)}}{\lambda n}
$$

\section{Optimal Monetary Policies}

We now investigate the optimal choice of monetary policy. Home and foreign governments choose monetary policy rules to maximize welfare for their domestic residents. Due to the oneperiod ahead pricing policies of firms, and the presence of complete markets, the equilibrium is stationary. Optimal monetary policies are obtained by maximizing expected utility for any period.

From a welfare perspective, the utility of real balances is likely to be of minor significance. Hence, following OR (1995, 1998) and Corsetti and Pesenti (1998), we ignore this term. Expected utility may be represented as

$$
E_{t-1} U_{t}=\frac{E_{t-1} C_{t}^{1-\rho}}{(1-\rho)}-\eta E_{t-1} L_{t}
$$

The choice of monetary policy rules may be represented as a game between home and foreign governments. The home government chooses the degree of foreign exchange rate intervention $\gamma$ and its response to home and foreign productivity shocks, taking the monetary rule of the foreign country government as given. The foreign government chooses its response to home and foreign productivity shocks, taking the home country monetary rule as given. The pair of monetary rules that satisfy these conditions form a Nash equilibrium of the monetary policy game. 


\section{3.a Producer Currency Pricing}

Under producer currency pricing, consumption and expected employment are identical in the home and the foreign country, so that both governments will face the same objective function. Using (2.5), (2.8) and (3.1), we may write common expected utility as

$$
E_{t-1} U_{t}=\frac{\left(E_{t-1} C_{t}\right)^{1-\rho} \exp \left(-\frac{\rho(1-\rho)}{2} \sigma_{c}^{2}\right)}{(1-\rho)}\left(\frac{\lambda-(1-\rho)(\lambda-1)}{\lambda}\right)
$$

Using the expressions for the mean and variance of consumption from the Appendix, the objective function under PCP can be written as

$$
E_{t-1} U_{t}=\Theta_{t} \exp (1-\rho)\left(-\frac{\sigma_{c}^{2}}{2}-\frac{n(1-n)}{2 \rho} \sigma_{s}^{2}-\frac{\tilde{\sigma}_{u}^{2}}{2 \rho}+\frac{\tilde{\sigma}_{c u}}{\rho}+n(1-n) \frac{\left(\sigma_{s u}-\sigma_{s u^{*}}\right)}{\rho}\right)
$$

where $\Theta_{t}=\left(\frac{\lambda \eta}{\lambda-1} \theta_{t-1}^{n \delta} \theta_{t-1}^{*(1-n) \delta}\right)^{\frac{1-\rho}{\rho}}\left(\frac{\lambda-(1-\rho)(\lambda-1)}{\lambda(1-\rho)}\right)$.

Equation (3.3) indicates that the objective function of the monetary authority under PCP is represented in a very simple form; minimize a linear function of consumption variance, exchange rate variance, and the covariance of consumption and the exchange rate with home and foreign productivity shocks. Given the simple assumptions of our model, the objective function for monetary policy becomes a quadratic, as in much of the earlier literature on optimal monetary rules based on more ad-hoc models and objective functions. The appeal of the present model however is that it delivers the appropriate welfare-based set of variables to be included in the objective function, and their relative weighting. Note also that monetary policy should explicitly take account of its effect on average consumption (and output). A Taylor series approximation to (3.2) around a constant average consumption level would lead us to conclude that minimizing consumption alone was the best objective for monetary policy; exchange rate variance and the covariance's with productivity shocks would be ignored. 
Given the dependence of consumption and the exchange rate on the monetary rules, we may implicitly write expected utility as: $E U=E U\left(\gamma, a_{1}, a_{2}, b_{1}, b_{2}\right)$.

A Nash equilibrium in monetary policies is defined as the set $\left\{\gamma^{N}, a_{1}^{N}, a_{2}^{N}, b_{1}^{N}, b_{2}^{N}\right\}$ which satisfies the problem P1,

P1

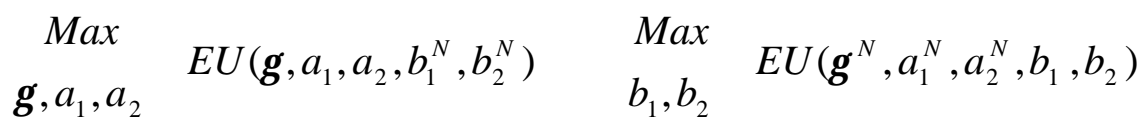

Both countries face the same objective function. So in fact it is clear that the solution to P1 is identical to the equilibrium of a cooperative monetary policy game, where the governments of both countries jointly choose the monetary rules to maximize joint welfare. Therefore, in the PCP environment, there are no gains to monetary policy coordination ${ }^{16}$.

We characterize the solution to P1 in two stages. First, we describe the solution for the monetary rules when there are only productivity shocks, holding the home country intervention rule $\gamma$ fixed. Then, we solve for the optimal intervention rule in the presence of monetary shocks.

\section{Productivity Shocks}

The values of $a_{1}, a_{2}, b_{1}, b_{2}$ that satisfy $\mathrm{P} 1$ are given by

$$
\begin{array}{ll}
a_{1}=1-\gamma-\frac{n i(\varepsilon-1)}{(1+i \varepsilon-\delta)} & a_{2}=\gamma-\frac{(1-n) i(\varepsilon-1)}{(1+i \varepsilon-\delta)} \\
b_{1}=1-\frac{(1-n) i(\varepsilon-1)}{(1+i \varepsilon-\delta)} & b_{2}=-\frac{n i(\varepsilon-1)}{(1+i \varepsilon-\delta)}
\end{array}
$$

For the foreign country government, the optimal monetary rule is to respond positively to foreign productivity shocks, but respond negatively (positively) to home country productivity shocks as $\varepsilon>1(\varepsilon<1)$. For the home country government, the optimal response to productivity

\footnotetext{
${ }^{16}$ If we had allowed discretionary monetary policy rather than a system of rules as in (2.1) and (2.2), policy coordination would make a difference - see Betts and Devereux (2000b).
} 
shocks depends on the degree of foreign exchange market intervention. With zero intervention, the rule is the mirror image of the foreign rule: respond positively to home country shocks and either negatively or positively to foreign shocks, depending on $\varepsilon$. But when there is positive exchange rate intervention, the response to productivity shocks for the home country may be in the opposite direction.

Monetary authorities attempt to use the rules (3.4) and (3.5) to sustain the flexible price allocation. Essentially, the economy has three departures from full efficiency. Prices are sticky, so consumption and employment do not respond to money and productivity shocks as they would in a flexible price environment. There are monopolistic competitive markups. Finally, there is a departure from the Friedman rule of zero nominal interest rates. The second loss cannot be affected by the monetary rules (2.1) and (2.2), since these rules cannot influence the markups obtained in Table 1. ${ }^{17}$ The third loss is neglected from the analysis because we ignore the utility of real balances. Thus, the best that the monetary policy rules can do is to attempt to replicate the flexible price equilibrium. ${ }^{18}$

To attain the flexible price allocation, the authorities must ensure that consumption equals (2.4). This requires that in the aggregate, monetary policy should react in a pro-cyclical manner to productivity shocks ${ }^{19}$. Take the case where there is only a home country productivity shock. Then in face of a $u$ shock, if the world money supply responds by $n \frac{(1+i-\delta)}{(1+i \varepsilon-\delta)}$, consumption variance is the same as in the flexible price equilibrium. But expected consumption would not necessarily be at its desired level. For instance, if both home and foreign monetary authorities reacted in the

\footnotetext{
${ }^{17}$ Although monetary policy rules do influence expected output levels in our model, they cannot eliminate the distortion from imperfect competition, because the markup depends only on constant elasticities. Gali and Monacelli (1999) show that the welfare impact of deviations from competitive pricing can be eliminated by a production subsidy to firms that operates independently of monetary policy. In our analysis, it is easy to show that an equivalent optimal production subsidy exists. But this does not affect any of our conclusions below.

${ }^{18}$ Similar observations in a related model have been made by OR (2000).
} 
identical manner, so as to achieve an average monetary policy response given by $n \frac{(1+i-\delta)}{(1+i \varepsilon-\delta)}$ the exchange rate would have zero variance. From (2.8) however, expected consumption would then be too low. In order to achieve the desired level of expected consumption, it is necessary that the exchange rate responds positively to $u$ shocks. This is facilitated by the monetary rules (3.4) and (3.5), which ensure that the home country money supply response is positive and exceeds that of the foreign country.

An alternative intuition on the role of exchange rate changes may be described in terms of the movements in employment. In order to achieve the optimal employment response in the home and foreign economy, it is necessary to alter world relative prices, through movements in the nominal exchange rate. In response to a home country productivity shock, the nominal exchange rate must depreciate, to ensure world demand is substituted towards the home country's products. For this, it is necessary that the home country monetary reaction to a home productivity shock is positive and exceeds that of the foreign country. Optimal monetary policy therefore relies on the expenditure switching mechanism of the exchange rate under the PCP pricing regime. The exchange rate movement in fact replicates the required terms of trade movement that would take place under fully flexible prices ${ }^{20}$.

It is easy to establish that with the monetary rules given in (3.4) and (3.5), the equilibrium under PCP replicates the flexible price allocation under productivity shocks alone. This can be shown by substituting (3.4) and (3.5) into (2.7) and deriving the expression for expected utility (3.2) with the optimal monetary rules, when $v=v^{*}=0$. An immediate implication of this is that exchange rate flexibility is a requirement for an optimal monetary policy rule, under PCP, in the

\footnotetext{
${ }^{19}$ Note the even if $\gamma$ is sufficiently positive that $a_{1}$ is negative, the overall money supply will still be increasing in $u$ shocks.

${ }^{20}$ The objective function (3.2) does not contain employment. But from (1.5) and (2.7) it may be established that there is an equivalence between using monetary rules to achieve the desired mean and variance of consumption and achieving the desired mean and variance of national employment levels.
} 
presence of productivity shocks. The optimal monetary policy is one that must not only ensure that distribution of consumption is identical to that under flexible nominal prices, but also that the distribution of the exchange rate is identical to that of the terms of trade under flexible prices. Exchange rate adjustment is necessary to achieve the desired terms of trade adjustment. This is the essence of Friedman's argument for floating exchange rates quoted in the introduction.

A critical aspect of the optimal monetary rules given in (3.4) and (3.5) is that they require participation by both monetary authorities. It is interesting to contrast problem P1 with an alternative case, where only the home monetary authority chooses optimal feedback rules, assuming that the foreign monetary authority follows a purely passive monetary policy, where $b_{i}=0, i=1,2$. Problem P2 is thus defined as

$\mathrm{P} 2$

$$
\underset{\gamma, a_{1}, a_{2}}{\operatorname{Max}} \operatorname{EU}\left(\gamma, a_{1}, a_{2}, 0,0\right)
$$

The optimal rules for $a_{1}$ and $a_{2}$ are now given by

$$
a_{1}=\frac{(\phi n+(1-n)-\psi n \rho \phi)}{\left((1-n)+\phi^{2} \rho n\right)}(1-\gamma) \quad a_{2}=\frac{(1-n)(\phi-1-\psi \rho \phi)}{\left((1-n)+\phi^{2} \rho n\right)}(1-\gamma)
$$

It can easily be established that $a_{1}$ is consistent with the solution for P1 only when $\varepsilon=1$, and $a_{2}$ is in general never consistent with the solution for P1. A policy maker optimizing alone cannot support the flexible price allocation. Take the case where $\varepsilon>1$. Under problem P1, the home monetary authority will expand money supply in response to a home country productivity shock, while the foreign authority will contract money supply. This achieves the right combination of increasing world demand and exchange rate depreciation. But with problem $\mathrm{P} 2$, the rule given by (3.4) would entail too high a response in consumption, since the foreign government does not respond to the disturbance. The optimal rule under P2 is to respond to domestic productivity shocks less than is indicated in rule (3.4). Consumption still rises by too much, while the exchange rate rises by too little, relative to $\mathrm{P} 1$. Also, in response to a foreign technology shock, the home 
government cannot adequately respond. The reason is that the desire to increase domestic consumption calls for a monetary expansion $\left(a_{2}>0\right)$, but the desire to generate a terms of trade improvement calls for a monetary contraction $\left(a_{2}<0\right)$. The optimal $a_{2}$ may therefore be either positive or negative.

\section{Monetary Shocks}

Given optimal choices $a_{i}$, the home country government chooses the degree of exchange rate intervention according to P1. From (2.6), we see that the optimal intervention rule is that which minimizes the following function of consumption variability and exchange rate variability:

$$
\frac{\sigma_{c}^{2}}{2}+n(1-n) \frac{\sigma_{s}^{2}}{2 \rho}
$$

The optimal intervention rule is given by

$$
\gamma=-\frac{\sigma_{v}^{2}}{\sigma_{v^{*}}^{2}}+(1-n)\left(1-\frac{1}{\rho \phi^{2}}\right)\left(1+\frac{\sigma_{v}^{2}}{\sigma_{v^{*}}^{2}}\right)
$$

The rule depends solely on monetary variability. It is independent of the distribution of real shocks. $^{21}$ The optimal intervention depends on the strength of home country monetary variability relative to foreign monetary variability. When foreign monetary variability tends to zero, $\gamma$ tends to negative infinity; i.e. the exchange rate is prevented from moving at all in response to monetary disturbances. This supports the traditional result that a fixed exchange rate regime is optimal when the only shocks arise from the domestic monetary sector. One might think then that a floating exchange rate $(\gamma=0)$ would be preferable when home country monetary variability becomes arbitrarily small. But in fact we see that as home country monetary variance gets arbitrarily small, the intervention coefficient approaches a limit of

\footnotetext{
${ }^{21}$ This property that the intervention rule is independent of the distribution of supply shocks will remain even if the authorities do not target supply shocks at all. If monetary rules (3.4) and (3.5) did not contain a response to supply shocks, the exchange rate would be independent of supply shocks. Therefore, the degree of exchange rate intervention could not alter the economy's response to supply shocks.
} 


$$
\gamma=(1-n)\left(1-\frac{1}{\rho \phi^{2}}\right)
$$

The optimal intervention in face of foreign monetary shocks will lie between a fixed exchange rate and a free float, when $\rho \phi^{2}>1$.

The reason that a free float is not in general desirable is that the authorities are not trying to minimize consumption variance only, but are also concerned with exchange rate variance. Floating exchange rates would tend to minimize the extent to which foreign monetary disturbances contribute to consumption variance, but would leave exchange rate variance too high. Excessive exchange rate variance has a welfare cost through the reduction in expected consumption. An optimal intervention rule will trade off the benefits of exchange rate adjustment in reducing consumption variance against the welfare costs of exchange rate variability itself.

\section{3.b Local Currency Pricing}

Under LCP, home and foreign consumption are not equated, because the real exchange rate is no longer constant. This implies that the objective functions for home and foreign governments will differ. For the home government, the objective function depends on expected consumption, consumption variance, and expected employment. Substituting (2.13) into expected utility given in (3.1), gives

$$
E_{t-1} U_{t}=E_{t-1} C_{t}^{1-\rho}\left(\frac{\lambda-n(\lambda-1)(1-\rho)}{\lambda(1-\rho)}\right)-\frac{(1-n)(\lambda-1)}{\lambda} E_{t-1} C_{t}^{*(1-\rho)}
$$

In a symmetric fashion, foreign country expected utility equals:

$$
E_{t-1} U_{t}^{*}=E_{t-1} C_{t}^{* 1-\rho}\left(\frac{\lambda-n(\lambda-1)(1-\rho)}{\lambda(1-\rho)}\right)-\frac{(1-n)(\lambda-1)}{\lambda} E_{t-1} C_{t}^{(1-\rho)}
$$

These functions may again be decomposed into means and variances of consumption. Then substituting for these values from the Appendix, we can establish: 


$$
\begin{gathered}
E_{t-1} C_{t}^{1-\rho} \propto \exp \left((1-\rho)\left(-\frac{\sigma_{c}^{2}}{2}-\frac{\tilde{\sigma}_{u}^{2}}{2 \rho}+\frac{\tilde{\sigma}_{c u}}{\rho}\right)\right. \\
E_{t-1} C_{t}^{*(1-\rho)} \propto \exp \left((1-\rho)\left(-\frac{\sigma_{c^{*}}^{2}}{2}-\frac{\tilde{\sigma}_{u}^{2}}{2 \rho}+\frac{\tilde{\sigma}_{c^{*} u}}{\rho}\right)\right.
\end{gathered}
$$

The optimal monetary rule with LCP requires policymakers to target a combination of two separate functions of consumption variance and the covariance between consumption and productivity

shocks. But because under LCP, foreign consumption is independent of the parameters of the home country monetary rule, the home country problem amounts to simply minimizing the expression:

$$
\frac{\sigma_{c}^{2}}{2}+\frac{\tilde{\sigma}_{u}^{2}}{2 \rho}-\frac{\tilde{\sigma}_{c u}}{\rho}
$$

An essential difference from the PCP case is that exchange rate volatility is no longer an independent argument in the objective function. ${ }^{22}$

The determination of monetary rules in the LCP case can be described as the Nash equilibrium $\left\{\gamma^{N}, a_{1}^{N}, a_{2}^{N}, b_{1}^{N}, b_{2}^{N}\right\}$

P3 $\begin{gathered}\operatorname{Max} \\ \gamma, a_{1}, a_{2}\end{gathered} \quad E U\left(\gamma, a_{1}, a_{2}, b_{1}^{N}, b_{2}^{N}\right) \quad \begin{aligned} & \operatorname{Max} \\ & b_{1}, b_{2}\end{aligned} \quad E U^{*}\left(\gamma^{N}, a_{1}^{N}, a_{2}^{N}, b_{1}, b_{2}\right)$

Again, we characterize the solution to P3 first in the presence of productivity shocks, and then we allow for monetary shocks and optimal intervention.

\section{Productivity Shocks}

The solution to $\mathrm{P} 3$, holding $\gamma$ constant, is given by

$$
a_{1}=n \frac{(1+i-\delta)}{(1+i \varepsilon-\delta)} \quad a_{2}=(1-n) \frac{(1+i-\delta)}{(1+i \varepsilon-\delta)}
$$

\footnotetext{
22 The parameters of the foreign country's money rule do enter into home country consumption as long as home engages in some exchange rate intervention. But in the first order conditions for the choice of the optimal policy rule for the foreign country, envelope conditions imply that this dependence is ignored.
} 


$$
b_{1}=a_{2}=a_{1}
$$

Again, as in the case of PCP, these rules ensure that consumption is identical across countries, and has the same variance as in the flexible price equilibrium. But unlike the case of PCP, these rules do not entail exchange rate adjustment. Each government responds in an identical way to a home or foreign productivity shock. The optimal monetary rules are consistent with a fixed exchange rate. $^{23}$

The reason that optimal monetary rules do not require exchange rate adjustment in the LCP case is that the exchange rate plays no role in determining expected consumption. Exchange rate changes do not pass-through to price levels and therefore do not influence wages. Thus, they do not influence either marginal costs or expected prices and expected consumption.

An equivalent perspective on the monetary rules (3.10) and (3.11) is that in the LCP case, exchange rate adjustment does not play a role in altering patterns of expenditure between home and foreign goods. Therefore, it cannot influence the determination of employment in either country. Optimal monetary policy no longer tries to move the exchange rate so as to achieve an optimal terms of trade adjustment, since the terms of trade do not influence demand or employment.

The absence of exchange rate movement in the optimal rules in the LCP environment is at variance with the Friedman/Mundell argument for exchange rate flexibility, and more generally with the conventional statement of the costs of a single currency area. In the conventional argument, countries that are subject to idiosyncratic real shocks will benefit from exchange rate adjustment in face of these shocks. This argument is borne out in the PCP case. But with LCP, even country-specific shocks do not require exchange rate movement as part of an optimal policy response. Thus, even in the presence of distinct country specific real disturbances, there is no

\footnotetext{
${ }^{23}$ Equation (A.17) of the appendix gives the exchange rate equation under LCP.
} 
sacrifice of macroeconomic adjustment by eliminating the exchange rate as a tool of macroeconomic management (when the predominant disturbances are country specific productivity shocks), if we take the institutional structure of goods pricing as given.

Although optimal monetary policy under LCP does not require exchange rate adjustment, a natural guess would be that the absence of exchange rate pass-through comes at a cost. This is correct. The optimal monetary policy under LCP does not support the full flexible price optimum. While the monetary rules (3.10) and (3.11) keep the response of home and foreign consumption equal to that at the flexible price optimum, they cannot ensure that employment in each country is identical to the flexible price optimum. Equivalently, the monetary rules lead consumption variance to match the flexible price equilibrium, but the mean level of consumption falls short of the flexible price equilibrium. Thus, the presence of LCP imposes welfare costs on the world as a whole, by preventing terms of trade adjustment from having macroeconomic effects.

Problem P3 describes an environment where both domestic and foreign governments choose an optimal response to productivity shocks. What happens when the home country alone chooses an optimal monetary policy, assuming that the foreign government follows a purely passive monetary growth rule? Defining a choice for the home country government analogous to P2 gives optimal monetary rules equal to:

$$
a_{1}=n \frac{(1+i-\delta)}{(1+i \varepsilon-\delta)}(1-\gamma \phi \rho) \quad a_{2}=(1-n) \frac{(1+i-\delta)}{(1+i \varepsilon-\delta)}(1-\gamma \phi \rho)
$$

Examining (3.12) allows us to establish that the home country consumption variance is identical to problem P3. But the foreign country consumption variance is not the same as under P3. Thus, as regards home country consumption, the home country government, acting alone, can do as well as it can when the foreign government also chooses optimal monetary policy. Unlike the PCP case, there is no alteration in the policy rules when governments act alone - the optimal rules support the same consumption process for the home government. Of course, because expected utility does 
depend upon both home and foreign consumption, overall welfare must be lower when the foreign country government does not follow an optimal rule.

\section{Monetary Shocks}

Under LCP, the government's choice of exchange rate intervention is designed simply to minimize the variance of consumption. The optimal exchange rate intervention rule is given by

$$
\gamma=-\frac{\sigma_{v}^{2}}{\rho \phi \sigma_{v^{*}}^{2}}
$$

Again, the rule trades off the benefit of a fixed exchange rate, insulating the economy from domestic monetary shocks, against the benefits of exchange rate adjustment, cushioning the economy from foreign monetary disturbances. Unlike the rule under PCP, the intervention rule under LCP will vary between fully fixed exchange rates to fully floating exchange rates, as the importance of home and foreign monetary disturbances change in relative terms. In particular, if there are no home monetary shocks at all, then the monetary authority should follow a clean float. This is because, unlike the PCP case, there are no independent costs of exchange rate volatility under LCP. The optimal intervention rule does not have to take account of the way in which intervention affects exchange rate volatility. When there are only foreign monetary disturbances, a floating exchange rate achieves the maximum insulation of home country consumption from the effects of the shocks.

When productivity shocks dominate, we have shown that welfare under LCP must be lower than that under PCP. But the same result does not apply in the case of money shocks. A simple example may be used to illustrate this. Say that the variance of productivity shocks is zero in both countries, and that money shocks have identical variance equal to $\sigma_{v}^{2}$ in both countries. Finally, imagine that the home country follows a zero exchange rate intervention rule (this is easily relaxed - see below). Then in the PCP case, expected utility is a positive function of 


$$
-\frac{\sigma_{c}^{2}}{2}-\frac{n(1-n) \sigma_{s}^{2}}{2 \rho}=-\frac{\phi^{2}\left(n^{2}+(1-n)^{2}\right) \sigma_{v}^{2}}{2}-\frac{n(1-n) \sigma_{v}^{2}}{\rho}
$$

Under the same conditions, expected utility under LCP is a positive function of

$$
-\frac{\sigma_{c}^{2}}{2}=-\frac{\phi^{2} \sigma_{v}^{2}}{2}
$$

From these two expressions, we see that the welfare comparison between PCP and LCP contains two elements. On the one hand, consumption variance is lower under PCP, because part of a monetary shock is dissipated through exchange rate adjustment. On the other hand, the exchange rate volatility driven by money shocks imparts a welfare cost under PCP, but does not under LCP. Expected utility is higher under LCP (PCP) whenever $\phi^{2} \rho>1(<1)$. In general, either inequality may be satisfied. Therefore, the welfare comparison across the two pricing specifications is ambiguous; the adjustment benefits of the exchange rate in response to monetary shocks are tempered by the welfare costs of exchange rate volatility.

\section{Conclusions}

The optimal response of monetary policy to exchange rates is an old theme in openeconomy macroeconomics. The novel aspect of this paper is that the analysis is undertaken within an expected-utility-maximizing framework in the presence of nominal rigidity. We find that the optimal monetary policy depends in a fundamental way on the type of price stickiness. Traditional studies have assumed prices are fully preset in the currency of the producer, so that exchange rate changes "pass through" one hundred percent to consumer prices. This modeling contrasts with the recent empirical evidence suggesting very small short-run responses of consumer prices to exchange-rate changes. When prices are not very responsive to exchange rates, monetary policymakers cannot rely on the exchange rate to provide the necessary adjustment to real shocks. To the extent that consumers do not interpret exchange-rate changes as relative price changes in the short 
run, monetary policy can only achieve an inferior outcome in which it is unable to control the relative demand for domestic and foreign goods. The benefits of floating exchange rates are diminished in the absence of strong expenditure-switching effects.

There is a new literature on open-economy monetary policy-making, based on models in which agents optimize. McCallum and Nelson (1999) and Svensson (2000) exemplify this recent work, which builds on the earlier work by Rotemberg and Woodford (1997). These models are, in many ways, more sophisticated than the model of this paper. In those models, prices adjust only slowly over time, while here prices adjust fully after one period. They allow for investment dynamics, while our model has ignored the role of investment in short-run macroeconomic dynamics. But in our model, firms' objectives are clearly integrated with the objectives of the firm owners. We allow for deviations from the law of one price, in contrast to this new literature. And, we do not take linear approximations around the steady state in solving the model. If we were to follow the techniques of this recent literature, we would lose the important insights about the effects of monetary policy on the expected levels of consumption and employment. Clearly a challenge for the future is to merge the best elements of the literature generated by OR $(1995,1998)$ with the research program initiated by Rotemberg and Woodford (1997).

Finally, our modeling strategy follows the recent literature in taking the currency of price setting as exogenous. A more sophisticated model would endogenize that choice. The choice of currency to set prices in may not be independent of the monetary policy regime. Devereux, Engel and Tille (1999) and Tille (2000) have enriched the current framework by introducing middlemen that buy from producers at prices set in the producers' currencies, and sell to consumers at prices set in consumers' currencies. We have noted that this model is equivalent to the one presented here under complete financial markets. When asset markets are less fully developed, the structure of the marketing and distribution scheme may depend on monetary and exchange rate regimes. The 
interaction between price setting and monetary policy is likely to be a fruitful area for future research into our understanding of optimal monetary policy in open economies.

\section{References}

Bacchetta, Philippe, and Eric van Wincoop, 1998, Does exchange rate stability increase trade and capital flows, Federal Reserve Bank of New York, working paper no. 9818.

Betts, Caroline and Michael B. Devereux, 1996, The exchange rate in a model of pricing-to-market, European Economic Review 40, 1007-1021.

Betts, Caroline, and Michael B. Devereux, 2000a, Exchange rate dynamics in a model of pricing-tomarket, Journal of International Economics 50, 215-244.

Betts, Caroline, and Michael B. Devereux, 2000b, International Monetary Policy Coordination and Competitive Depreciation: A Re-evaluation, Journal of Money Credit and Banking, forthcoming.

Chari, V.V.; Patrick J. Kehoe; and, Ellen McGrattan, 1997, Monetary policy and the real exchange rate in sticky price models of the international business cycle, National Bureau of Economic Research, working paper no. 5876.

Cole, Harold L., and Maurice Obstfeld, 1991, Commodity trade and international risk sharing: How much do financial markets matter?, Journal of Monetary Economics 23, 377-400.

Corsetti, Giancarlo, and Paolo Pesenti, 1997, Welfare and macroeconomic interdependence, National Bureau of Economic Research, working paper no. 6307.

Devereux, Michael B., and Charles Engel, 1998, Fixed vs. floating exchange rates: How price setting affects the optimal choice of exchange-rate regime, National Bureau of Economic Research, working paper no. 6867.

Devereux, Michael B.; Engel, Charles; and, Cedric Tille, 1999, Exchange rate pass-through and the welfare effects of the euro, National Bureau of Economics, working paper no. 7382. 
Eichengreen, Barry, 1994, International monetary arrangements for the 21st century (Washington, D.C.: Brookings Institution.)

Engel, Charles, 1993, Real exchange rates and relative prices: An empirical investigation, Journal of Monetary Economics 32, 35-50.

Engel, Charles, 1999, Accounting for U.S. real exchange rate changes, Journal of Political Economy $107,507-538$.

Engel, Charles, and John H. Rogers, 1996, How wide is the border?, American Economic Review $86,1112-1125$.

Feldstein, Martin, 1992, The case against the EMU, The Economist (June 13 $\left.{ }^{\text {th }}, 1992\right), 19-22$.

Frankel, Jeffrey, 1999, No single currency regime is right for all countries or at all times, National Bureau of Economic Research, working paper no. 7338.

Friedman, Milton, 1953, The case for flexible exchange rates, in Essays in Positive Economics (Chicago: University of Chicago Press), 157-203.

Gali, Jordi and Tommaso Monacelli (1999), "Optimal Monetary Policy and Exchange Rate Variability in a Small Open Economy" mimeo Boston College

Ghosh, Atish R., Anne-Marie Gulde, Jonathan D. Ostry, and Holger C. Wolf (1997) 'Does the Nominal Exchange Rate Regime Matter?', National Bureau of Economic Research, working paper no. 5864 .

McCallum, Bennett and E. Nelson, 1999, Nominal income targeting in an open-economy optimizing model, Journal of Monetary Economics 43, 553-578.

Mundell, Robert A., 1961, A theory of optimum currency areas, American Economic Review 51, $509-517$.

Mussa, Michael, 1986, Nominal exchange rate regimes and the behavior of real exchange rates: Evidence and implications, Carnegie-Rochester Conference Series on Public Policy 36, 163209. 
Obstfeld, Maurice, 1997, Europe's gamble, Brookings Papers on Economic Activity, no. 2, 241317.

Obstfeld, Maurice, 1998, Open economy macroeconomics: Developments in theory and policy, Scandinavian Journal of Economics, 100, 247-275.

Obstfeld, Maurice and Kenneth Rogoff, 1996, Foundations of International Macroeconomics, MIT Press, Cambridge, MA

Obstfeld, Maurice and Kenneth Rogoff, 1995, Exchange rate dynamics redux, Journal of Political Economy 103, 624-660.

Obstfeld, Maurice and Kenneth Rogoff, 1998, Risk and exchange rates, National Bureau of Economic Research, working paper no. 6694.

Obstfeld, Maurice and Kenneth Rogoff, 2000, New directions for stochastic open economy models, Journal of International Economic 50, 117-153.

Rotemberg, Julio J. and Michael Woodford, 1997, An optimization-based econometric framework for the evaluation of monetary policy, NBER Macroeconomics Annual, 297-346.

Sachs, Jeffrey, 1997, Personal views, Financial Times of London (July 30, 1997).

Svensson, Lars E.O., 2000, Open-economy inflation targeting, Journal of International Economics $50,155-183$.

Takagi, Shinji, and Yushi Yoshida (1999) Exchange Rate Movements and Tradable Goods Prices in East Asia: An Analysis Based on Japanese Customs Data, 1988-98, IMF Working Paper WP/99/31

Tille, Cédric, 2000, 'Beggar-thy-neighbor' or 'beggar-thyself'? The income effect of exchange rate fluctuations, Federal Reserve Bank of New York, working paper. 


\section{Appendix}

\section{Consumers}

The indexes of consumption of home and foreign goods are given by:

$$
C_{h}=\left[n^{-1 / \lambda} \int_{0}^{n} C_{h}(i)^{\lambda-1 / \lambda} d i\right]^{\lambda / \lambda-1} ; \quad C_{f}=\left[(1-n)^{-1 / \lambda} \int_{n}^{1} C_{f}(i)^{\lambda-1 / \lambda} d i\right]^{\lambda / \lambda-1} .
$$

The price indexes for home and foreign goods are given by:

$$
P_{h}=\left[\frac{1}{n} \int_{0}^{n} P_{h}(i)^{1-\lambda} d i\right]^{1 / 1-\lambda}, \quad P_{f}=\left[\frac{1}{1-n} \int_{n}^{1} P_{f}(i)^{1-\lambda} d i\right]^{1 / 1-\lambda} .
$$

The intratemporal decisions by households can be characterized by the following relationships:

$$
\begin{array}{cc}
C_{h}(i)=\frac{1}{n}\left[\frac{P_{h}(i)}{P_{h}}\right]^{-\lambda} C_{h}, & C_{f}(i)=\frac{1}{1-n}\left[\frac{P_{f}(i)}{P_{f}}\right]^{-\lambda} C_{f} ; \\
P_{h} C_{h}=n P C, & P_{f} C_{f}=(1-n) P C \\
\int_{0}^{n} P_{h}(i) C_{h}(i) d i=P_{h} C_{h}, & \int_{n}^{1} P_{f}(i) C_{f}(i) d i=P_{f} C_{f} .
\end{array}
$$

\section{Firms}

The optimization problem can be expressed as maximizing the expected present value of profits using the market nominal discount factor for the owners of the firm. Given that there is no intertemporal aspect to the firms' optimization problems (see, Obstfeld and Rogoff (1998)), this reduces to maximizing in the $\mathrm{PCP}$ case:

$$
n E_{t-1}\left[d_{t} \pi_{t}(i)\right]=E_{t-1}\left[d_{t}\left(\left(P_{h t}(i)-W_{t}\right)\left(X_{h t}(i)+X_{h t}^{*}(i)\right)\right)\right],
$$

where $X_{h t}(i)=n C_{h t}(i)$ is total sales of firm $i$ to home residents and $X_{h t}^{*}(i)=(1-n) C_{h t}^{*}(i)$ is total sales to foreign residents. 
In the LCP model, the firm chooses two different prices - one to charge residents of its own country, and one to charge residents of the other country. The typical home firm maximizes:

$$
E_{t-1}\left[d_{t-1}\left(P_{h t}(i) X_{h t}(i)+S_{t} P_{h t}^{*}(i) X_{h t}^{*}(i)-W_{t}\left(X_{h t}(i)+X_{h t}^{*}(i)\right)\right)\right] .
$$

Optimal prices in both cases are presented in Table 1 in the text.

\section{Money Demand Approximation}

The money market equilibrium condition (1.2) may be approximated by first writing (1.2) as:

$$
1-\left(\frac{P_{t}}{M_{t}}\right)^{\varepsilon} C_{t}^{\rho} \chi=\beta E_{t} \frac{P_{t} C_{t}^{\rho}}{P_{t+1} C_{t+1}^{\rho}}
$$

The right hand side may be expressed as

$$
\beta E_{t} \frac{P_{t} C_{t}^{\rho}}{P_{t+1} C_{t+1}^{\rho}}=\beta \exp \left(p_{t}+\rho c_{t}-E_{t} p_{t+1}+\frac{\sigma_{p}^{2}}{2}-\rho E_{t-1} c_{t+1}+\rho^{2} \frac{\sigma_{c}^{2}}{2}-\rho \sigma_{c p}\right)
$$

The left-hand side of (A.1) may be approximated around a steady state where the nominal interest rate is constant, so that $\beta E_{t} \frac{P_{t} C_{t}^{\rho}}{P_{t+1} C_{t+1}^{\rho}}=\frac{1}{1+i}$. This gives

$$
\ln \left(1-\frac{P_{t}}{M_{t}} C_{t}^{\frac{\rho}{\varepsilon}} \chi^{\frac{1}{\varepsilon}}\right) \approx \ln \left(\frac{1}{1+i}\right)+i\left(\varepsilon\left(m_{t}-p_{t}\right)-\rho c_{t}\right)+i \ln \left(\frac{i}{1+i} \chi^{-1}\right)
$$

Equating the log of (A.2) and (A.3) gives the money market clearing condition (2.3) of the text. 


\section{Solution for PCP Specification}

Under PCP, there is full PPP at all times, so we have $P_{t}=S_{t} P_{t}^{*}$ and $C_{t}=C_{t}^{*}$. By subtracting the foreign country money market clearing condition from the home condition, using PPP and the assumption of random walk money supply, we may derive a solution for the exchange rate given by

$$
s_{t}=\Gamma_{s}+m_{t}-m_{t}^{*},
$$

where $\Gamma_{s}$ is a constant.

Now from (1.3) (and its foreign equivalent), and the pricing equations in Table 1, we may write implicitly the equation which determines the period t- 1 expected value of consumption as

$$
1=\frac{\lambda}{\lambda-1} \eta \frac{\left(E_{t-1}\left(\frac{C_{t} S_{t}^{1-n}}{\theta_{t}}\right)\right)^{n}\left(E_{t-1}\left(\frac{C_{t} S_{t}^{-n}}{\theta_{t}^{*}}\right)\right)^{1-n}}{E_{t-1}\left(C_{t}^{1-\rho}\right)}
$$

Now using (A.4) and (A.5), imposing the fact that the solution for consumption and the exchange rate will be log-normal, and taking logs, we may solve for the value of expected consumption as

$$
\begin{aligned}
E_{t-1} c_{t} & =-\frac{1}{\rho} \ln \left(\frac{\lambda \eta}{\lambda-1}\right)-\frac{(2-\rho)}{2} \sigma_{c}^{2}-\frac{n(1-n)}{2 \rho} \sigma_{s}^{2}+\delta \frac{\left(n \ln \theta_{t-1}+(1-n) \ln \theta_{t-1}^{*}\right)}{\rho} \\
& -\frac{\left(n \sigma_{u}^{2}+(1-n) \sigma_{u^{*}}^{2}\right)}{2 \rho}+\frac{\left(n \sigma_{c u}+(1-n) \sigma_{c u^{*}}\right)}{\rho}+n(1-n) \frac{\left(\sigma_{s u}-\sigma_{s u^{*}}\right)}{\rho}
\end{aligned}
$$

Now combine the home and foreign money market equilibrium conditions to obtain the equation:

$$
\tilde{m}_{t}-\tilde{p}_{t}=\frac{\rho}{\varepsilon} c_{t}-\frac{\rho}{i \varepsilon}\left(E_{t} c_{t+1}-c_{t}\right)-\frac{1}{i \varepsilon}\left(E_{t} \tilde{p}_{t+1}-\tilde{p}_{t}\right)+\Gamma_{m}
$$


where $\Gamma_{m}$ is a constant, and $\tilde{p}_{t}=n p_{h t}+(1-n) p_{f t}^{*}, \tilde{m}_{t}=n m_{t}+(1-n) m_{t}^{*}$. Using (A6), taking expectations dated period $\mathrm{t}-1$, and solving for $\tilde{p}_{t}$ gives:

$$
\tilde{p}_{t}=-\Gamma_{m}+\tilde{m}_{t-1}-\delta \frac{(1+i-\delta)}{(1+i \varepsilon-\delta)}\left(n \ln \theta_{t-1}+(1-n) \ln \theta_{t-1}^{*}\right)
$$

Using (A.7) and (A.8), we may solve for time $t$ consumption as :

$$
c_{t}=E_{t-1} c_{t}+\phi\left(\tilde{m}_{t}-\tilde{m}_{t-1}\right)+\psi\left(n u_{t}+(1-n) u_{t}^{*}\right)
$$

where

$$
\phi=\frac{(1+i \varepsilon)}{\rho(1+i)} \quad \text { and } \quad \psi=\frac{\delta i(\varepsilon-1)}{\rho(1+i)(1+i \varepsilon-\delta)} .
$$

Now assume that governments follow the following monetary rules given in equations (2.1) and (2.2). Substituting these two equations into (A.4), we obtain the solution for the exchange rate given by equation (2.6).

Substituting (2.1) and (2.2) in (A.9), using the exchange rate solution (A.10), we obtain the solution for consumption given in equation (2.7).

The variance of the log of consumption can be calculated from equation (2.7) and is reported in Table A1. We can obtain the expected level of consumption by using the relationship

$$
E_{t-1} C_{t}=\exp \left(E_{t-1} c_{t}+\frac{1}{2} \sigma_{c}^{2}\right)
$$

and using equation (A.6). Equation (2.8) gives expected consumption.

To evaluate welfare, we must compute expected utility, including expected utility from employment. Employment for the home country may be written as in equation (1.5). Using the pricing equation from Table 1, we may write expected employment as in equation (2.9). Substituting this into expected utility gives equation (3.2). 
By the properties of the lognormal distribution

$$
E_{t-1} C_{t}^{1-\rho}=\exp (1-\rho)\left(E_{t-1} c_{t}+\frac{(1-\rho)}{2} \sigma_{c}^{2}\right)
$$

Using the expression for $E_{t-1} c_{t}$ in (A.6) and for $\sigma_{c}^{2}$ from Table A1, we can derive equation (3.3).

\section{Solution for the LCP specification}

Under the LCP specification, PPP does not generally hold, and so there is a failure of full risksharing. By using equation (1.3) and its foreign equivalent, the risk-sharing condition (1.4), and the pricing equations in Table 1, we may write the equation which implicitly defines expected home country consumption as

$$
1=\frac{\lambda}{\lambda-1} \eta \frac{E_{t-1}\left(\frac{C_{t}}{\theta_{t}}\right)^{n} E_{t-1}\left(\frac{C_{t}}{\theta_{t}^{*}}\right)^{1-n}}{E_{t-1}\left(C_{t}^{1-\rho}\right)}
$$

Using the log-normality assumption, and taking logs, we may solve for expected consumption as

$$
\begin{aligned}
E_{t-1} c_{t} & =-\frac{1}{\rho} \ln \left(\frac{\lambda \eta}{\lambda-1}\right)-\frac{(2-\rho)}{2} \sigma_{c}^{2}+\delta \frac{\left(n \ln \theta_{t-1}+(1-n) \ln \theta_{t-1}^{*}\right)}{2 \rho} \\
& -\frac{\left(n \sigma_{u}^{2}+(1-n) \sigma_{u^{*}}^{2}\right)}{2 \rho}+\frac{\left(n \sigma_{c u}+(1-n) \sigma_{c u^{*}}\right)}{\rho}
\end{aligned}
$$

A similar procedure establishes that

$$
\begin{aligned}
E_{t-1} c_{t}^{*} & =-\frac{1}{\rho} \ln \left(\frac{\lambda \eta}{\lambda-1}\right)-\frac{(2-\rho)}{2} \sigma_{c^{*}}^{2}+\delta \frac{\left(n \ln \theta_{t-1}+(1-n) \ln \theta_{t-1}^{*}\right)}{\rho} \\
& -\frac{\left(n \sigma_{u}^{2}+(1-n) \sigma_{u^{*}}^{2}\right)}{2 \rho}+\frac{\left(n \sigma_{c^{*} u}+(1-n) \sigma_{c^{*} u^{*}}\right)}{\rho}
\end{aligned}
$$

The critical difference from (A.6) is that exchange rate variability does not affect expected consumption. 
From the home economy money market clearing condition (2.3), taking expectations, and using (A.13), we may solve for the home price level as

$$
p_{t}=-\Gamma_{m}+m_{t-1}-\delta \frac{(1+i-\delta)}{(1+i \varepsilon-\delta)}\left(n \ln \theta_{t-1}+(1-n) \ln \theta_{t-1}^{*}\right)
$$

Home consumption is determined again from the home money market clearing condition as

$$
c_{t}=E_{t-1} c_{t}+\phi\left(m_{t}-m_{t-1}\right)+\psi\left(n u_{t}+(1-n) u_{t}^{*}\right)
$$

We can use the risk-sharing condition (1.4), the money-market equilibrium conditions, and equation (A.15) to solve for the exchange rate as:

$$
s_{t}=\rho \phi\left(m_{t}-m_{t}^{*}\right)-\frac{i(\varepsilon-1)}{1+i}\left(p_{t}-p_{t}^{*}\right)+\Gamma_{s},
$$

where $\Gamma_{s}$ is a constant term.

Assume that the monetary policy rules followed by the home and foreign governments are given by (2.1) and (2.2). Then we can use equation (A.17) to write home monetary policy as

$$
m_{t}-m_{t-1}=\frac{1}{1-\phi \rho \gamma}\left(a_{1} u_{t}+a_{2} u_{t}^{*}+v_{t}\right)-\frac{\phi \rho \gamma}{1-\phi \rho \gamma}\left(b_{2} u_{t}+b_{1} u_{t}^{*}+v_{t}^{*}\right)
$$

Substituting (A.18) into (A.16) gives equation (2.10). The variance of the log of consumption can be derived directly from equation (2.10), and is reported in Table A1. The expected level of consumption can be derived as before using the relationship in equation (A.10), and is given in equation (2.12). Using (1.6), and the pricing rules in Table 1, we may write expected employment as (2.13). 


\begin{tabular}{|c|c|}
\hline \multicolumn{2}{|c|}{ Table A1 } \\
\hline Vlexible Prices & $\frac{n^{2} \sigma_{u}^{2}+(1-n)^{2} \sigma_{u^{*}}^{2}}{\rho^{2}}$ \\
\hline PCP & $\phi^{2}\left(\frac{n^{2}}{(1-\gamma)^{2}} \sigma_{v}^{2}+\frac{(1-\gamma-n)^{2}}{(1-\gamma)^{2}} \sigma_{v^{*}}^{2}\right)+\Lambda_{1}^{2} \sigma_{u}^{2}+\Lambda_{2}^{2} \sigma_{u^{*}}^{2}$ \\
\hline PTM (Home) & $\phi^{2}\left(\frac{1}{(1-\gamma \phi \rho)^{2}} \sigma_{v}^{2}+\frac{(\phi \rho \gamma)^{2}}{(1-\gamma \phi \rho)^{2}} \sigma_{v^{*}}^{2}\right)+\Omega_{1}^{2} \sigma_{u}^{2}+\Omega_{2}^{2} \sigma_{u^{*}}^{2}$ \\
\hline PTM (Foreign) & $\phi^{2}\left(\sigma_{v^{*}}^{2}\right)+\Omega_{2}^{* 2} \sigma_{u}^{2}+\Omega_{1}^{* 2} \sigma_{u^{*}}^{2}$ \\
\hline & $\phi=\frac{(1+i \varepsilon)}{\rho(1+i)} \quad \psi=\frac{\delta i(\varepsilon-1)}{\rho(1+i)(1+i \varepsilon-\delta)}$ \\
\hline
\end{tabular}




\begin{tabular}{|c|c|}
\hline & Table A2 \\
\hline & Expected Value of Consumption \\
\hline Flexible Prices & $E_{t-1} C_{t}=\left(\frac{\lambda \eta}{\lambda-1}\right)^{-\frac{1}{\rho}}\left(\theta_{t-1}^{\delta n} \theta_{t-1}^{* \delta(1-n)}\right)^{\frac{1}{\rho}} \exp \left(\frac{1}{\rho^{2}} \frac{n^{2} \sigma_{u}^{2}+(1-n)^{2} \sigma_{u^{*}}^{2}}{2}\right)$ \\
\hline PCP & $\begin{aligned} & E_{t} C_{t-1}=\left(\frac{\lambda \eta}{\lambda-1}\right)^{-\frac{1}{\rho}}\left(\theta_{t-1}^{\delta n} \theta_{t-1}^{* \delta(1-n)}\right) \frac{1}{\rho} \exp \left(-\frac{(1-\rho) \sigma_{c}^{2}}{2}-\frac{n(1-n)}{2 \rho} \sigma_{s}^{2}\right) \\
\times & \exp \left(-\frac{n \sigma_{u}^{2}+(1-n) \sigma_{u^{*}}^{2}}{2 \rho}+\frac{n \sigma_{c u}+(1-n) \sigma_{c u^{*}}}{\rho}+n(1-n) \frac{\left(\sigma_{s u}-\sigma_{\left.s u^{*}\right)}\right.}{\rho}\right)\end{aligned}$ \\
\hline PTM (Home) & $\begin{array}{c}E_{t-1} C_{t}=\left(\frac{\lambda \eta}{\lambda-1}\right)^{-\frac{1}{\rho}}\left(\theta_{t-1}^{\delta n} \theta_{t-1}^{* \delta(1-n)}\right)^{\frac{1}{\rho}} \exp \left(-\frac{(1-\rho) \sigma_{c}^{2}}{2}-\frac{n \sigma_{u}^{2}+(1-n) \sigma_{u^{*}}^{2}}{2 \rho}\right) \\
\quad \times \exp \left(\frac{n \sigma_{c u}+(1-n) \sigma_{c u^{*}}}{\rho}\right)\end{array}$ \\
\hline PTM (Foreign) & $\begin{array}{c}E_{t} C_{t-1}^{*}=\left(\frac{\lambda \eta}{\lambda-1}\right)^{-\frac{1}{\rho}}\left(\theta_{t-1}^{\delta n} \theta_{t-1}^{* \delta(1-n)}\right) \frac{1}{\rho} \exp \left(-\frac{(1-\rho) \sigma_{c^{*}}^{2}}{2}-\frac{n \sigma_{u}^{2}+(1-n) \sigma_{u^{*}}^{2}}{2 \rho}\right. \\
\quad \times \exp \left(\frac{n \sigma_{c^{*} u}+(1-n) \sigma_{c^{*} u^{*}}}{\rho}\right)\end{array}$ \\
\hline & $\phi=\frac{(1+i \varepsilon)}{\rho(1+i)} \quad \psi=\frac{\delta i(\varepsilon-1)}{\rho(1+i)(1+i \varepsilon-\delta)}$ \\
\hline
\end{tabular}

